\title{
Polymerization of Methacrylic Esters Using Metal Alkoxides Containing Lanthanoids
}

\author{
Shigeki Habaue, Mayumi YoshiKawa, and Yoshio OKamoto* \\ Department of Applied Chemistry, School of Engineering \\ Nagoya University, Nagoya 464-01, Japan
}

(Received February 2, 1995)

\begin{abstract}
Polymerization of methyl methacrylate (MMA) was promoted by the clusters of lithium isopropoxide containing lanthanoid(III) isopropoxides $\left[\mathrm{La}(\mathrm{O} i-\mathrm{Pr})_{3}(\mathbf{1})\right.$ and $\mathrm{Ce}(\mathrm{O} i \text {-Pr })_{3}$ (2)], prepared from the corresponding lanthanoid(III) chlorides according to the Kagan's method. The initiators provided an isotactic poly(MMA) in a good yield, although lithium isopropoxide afforded no polymer in toluene at $0^{\circ} \mathrm{C}$. While lithium isopropoxide also gave no polymer in tetrahydrofuran at $0^{\circ} \mathrm{C}$, syndiotactic poly(MMA) was obtained even at $-40^{\circ} \mathrm{C}$ using the cerium triisopropoxide (2) in $91 \%$ yield. The polymerization was confirmed to be initiated through Meerwein-Ponndorf-Verley (MPV) reduction.

KEY WORDS Meerwein-Ponndorf-Verley Reduction / Metal Alkoxide / Lanthanoid(III) Isopropoxide / Methyl Methacrylate / Benzyl Methacrylate / Poly(methacrylic ester) / Cluster / Anionic Polymerization /
\end{abstract}

Meerwein-Ponndorf-Verley (MPV) reduction is one of the most important methods to transform carbonyl compounds to alcohols. ${ }^{2}$ However, as far as we know, there is no example in which polymerization is initiated through MPV reduction by metal alkoxides, although a large number of researches on MPV reduction have been reported including asymmetric reactions in organic synthesis. ${ }^{3}$ Generally aluminum triisopropoxide is used as a typical reagent in MPV reduction, and it is well known that the reaction conditions are relatively hard and an excess of 2-propanol is necessary. These should be the reasons for difficulty of application of MPV reduction to anionic polymerization. Herein we wish to report the first example of the polymerization of methacrylic esters initiated through MPV reduction.

Recently, lanthanoid compounds have been of interest in the area of synthetic organic and

\footnotetext{
* To whom all correspondence should be addressed.
}

polymer chemistry, and many characteristic reactions have been developed. ${ }^{4}$ Kagan and co-workers reported a convenient synthesis of lanthanoid alkoxides and its efficient application to some organic reactions in catalysis, especially to Meerwein-Ponndorf-VerleyOppenauer reactions. ${ }^{1}$ So we attempted to investigate the polymerization activity and characteristics of the lanthanoid triisopropoxide prepared by the Kagan's method as an initiator.

\section{EXPERIMENTAL}

\section{General Methods}

Column chromatography was conducted by using silica gel 60 (E. Merck 9385, 230-400 mesh). ${ }^{1} \mathrm{H}$ NMR spectra were measured on a Varian VXR-500S $(500 \mathrm{MHz})$ or Gemini-200 $(200 \mathrm{MHz})$ spectrometer in $\mathrm{CDCl}_{3}$ with tetramethylsilane as the internal standard. Analyti- 
cal gas chromatography (GC) was performed on a Yanaco G2800 instrument eguipped with a flame ionization detector and a capillary column of PoraPLOT Q $(0.32 \times 25000 \mathrm{~mm})$ using helium as carrier gas. Mass spectra were recorded with a JEOL JMS-AX505HA mass spectrometer. Gel permeation chromatography (GPC) was performed on a JASCO 880-PU chromatograph equipped with a JASCO MD910 or JASCO 830-RI detector by using a series of TSK $3000 \mathrm{H}+$ Shodex KF-80M + Shodex A-80M GPC columns (eluent: THF). The obtained chromatogram was calibrated against standard polystyrene samples. UV spectra of the lanthanoid triisopropoxide were measured in pentane using $0.5 \mathrm{~mm}$ cell on a JASCO Ubest-55 spectrophotometer. Inductively coupled plasma (ICP) analysis was carried out using $0.1 \mathrm{~N} \quad \mathrm{HNO}_{3}$ aqueous solution as a solvent with a Jarrel-Ash plasma atom-comp MK-II instrument.

Lanthanum chloride heptahydrate and cerium chloride heptahydrate were purchased from Nacalai Tesque and used after transformation to 2-propanol complexes $\left(\mathrm{LnCl}_{3} \cdot 3 i\right.$ - $\mathrm{PrOH}$; $\mathrm{Ln}=\mathrm{La}, \mathrm{Ce}) .^{1,5}$ MMA was first purified by fractional distillation from calcium hydride, and then distilled under high vacuum from fresh calcium hydride just before polymerization. Benzyl methacrylate (BnMA) was distilled over calcium hydride twice. The solvents [toluene, tetrahydrofuran (THF)] used in polymerization were distilled from $\mathrm{Na}$ wire, and then distilled again from $n$-BuLi for toluene and $\mathrm{LiAlH}_{4}$ for THF under high vacuum just before use.

\section{Synthesis of Cerium Triisopropoxide $[\mathrm{Ce}(\mathrm{O} i$ -}

$\mathrm{Pr}_{3}$ (2)] (Scheme 1)

Lanthanoid(III) triisopropoxides were prepared according to the Kagan's method. ${ }^{1}$ The synthetic route is shown in Scheme 1. All manipulation was carried out under an atmosphere of argon gas. To a suspension of 2propanol complex of cerium chloride $\left(\mathrm{CeCl}_{3}\right.$. $3 i-\mathrm{PrOH})(4.4 \mathrm{~g}, 10.3 \mathrm{mmol})$ in pentane $(20$

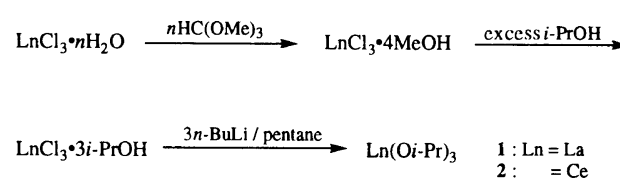

Scheme 1.

$\mathrm{mL}$ ) was added a solution of $n$-BuLi in hexane $(1.6 \mathrm{M}, 30.6 \mathrm{mmol})$ at $0^{\circ} \mathrm{C}$. After being stirred for $30 \mathrm{~min}$, the mixture was warmed to $35^{\circ} \mathrm{C}$ and the stirring was continued for $1.5 \mathrm{~h}$. After filtration of the reaction mixture, the obtained dark red solution was used for polymerization without further purification. The concentration of cerium ion was determined by ICP analysis.

The molecular weight determined by cryoscopic method in benzene was estimated about $1010-1240\left[\Delta T=0.08-0.10^{\circ} \mathrm{C}\right.$ on $2(0.22 \mathrm{~g})$ in benzene $(10.90 \mathrm{~g})]$. The concentrations of $\mathrm{Ce}^{3+}$ and $\mathrm{Li}^{+}$were determined to be $0.05 \mathrm{M}$ and $0.68 \mathrm{M}$, respectively, by ICP analysis, and that of $\mathrm{Cl}^{-} 0.12 \mathrm{M}$ by titration with silver nitrate using potassium chromate as an indicator on the solution of $\mathbf{2}$ in pentane.

\section{Polymerization of Methyl Methacrylate (MMA) Using $\mathrm{Ce}(\mathrm{Oi}-\mathrm{Pr})_{3}$ (2) System (Table I, Entry 4)}

Polymerization was carried out in a dry nitrogen atmosphere. MMA (1.2 g, $12 \mathrm{mmol})$ and toluene $(10 \mathrm{~mL})$ were added in a dry glass ampule with syringes, and the solution was cooled to $0^{\circ} \mathrm{C}$. To this solution was added a solution of 2 system in pentane $(0.05 \mathrm{M}$, $0.085 \mathrm{mmol}$ ) with a syringe. After $1 \mathrm{~h}$, the polymerization was terminated by adding a small amount of methanol. The product was precipitated in a large amount of methanol (ca. $150 \mathrm{~mL}$ ) containing a small amount of $1 \mathrm{~N}$ $\mathrm{HCl}$, and collected by centrifuge. The obtained polymer was dissolved in benzene, filtered, and then freeze-dried to afford poly(MMA) $(1.1 \mathrm{~g}$, $89 \%$ yield). The tacticity, $\mathrm{Mn}$, and $M_{w} / M_{n}$ were determined by analysis of ${ }^{1} \mathrm{H}$ NMR $\left(60^{\circ} \mathrm{C}\right.$ in $\left.\mathrm{CDCl}_{3}\right)^{6}$ and GPC; tacticity: $m m / m r / r r=$ 79/16/5, number-average molecular weight: $M_{n}=4.1 \times 10^{4}$, polydispersity: $M_{w} / M_{n}=2.6$. 
The methanol soluble oligomer was obtained in $<2 \%$ yield.

\section{Synthesis of Lithium Free Lanthanum Triiso- propoxide $\left[\mathrm{La}(\mathrm{O} i-\mathrm{Pr})_{3}(3)\right]^{7}$}

A solution of sodium isopropoxide, prepared by dissolving sodium metal $(1.9 \mathrm{~g}, 83 \mathrm{mmol})$ in a mixture of 2-propanol $(20 \mathrm{~mL})$ and benzene $(100 \mathrm{~mL})$, was transferred to the solution of 2-propanol complex of lanthanum chloride $(12.0 \mathrm{~g}, 28 \mathrm{mmol})$ in 2-propanol $(20 \mathrm{~mL})$ with stirring. The mixture was refluxed for $3 \mathrm{~h}$ (bath temp $=c a .120^{\circ} \mathrm{C}$ ). After standing overnight at room temperature, the precipitates were filtered. The solvents, benzene and 2-propanol, were distilled out and the residue was vacuumdried. The obtained white solid was dissolved in hexane and the solution was filtered to remove the residual sodium chloride. After concentration and vacuum-drying, the product (3) $(7.6 \mathrm{~g}, 86 \%$ yield) was used as a benzene solution (colorless and clear), without further purification; ICP analysis: $\mathrm{La}^{3+}=0.4 \mathrm{M}, \mathrm{Na}^{+}=$ $1.4 \mathrm{M}$; titration with silver nitrate: $\mathrm{Cl}^{-}=0.09$ M.

\section{Polymerization of MMA with a Solution of 3 System in Benzene}

The polymerization was carried out using the initiator ( 3 system, 1 equiv) and MMA (48 equiv) at $0^{\circ} \mathrm{C}$ for $2 \mathrm{~h}$ in toluene. In the case when lithium isopropoxide was used as a co-initiator, the procedure is as follows: To a solution of lithium isopropoxide $(1.2 \mathrm{mmol})$ in toluene $(10 \mathrm{~mL})$ was added a solution of 3 $(0.4 \mathrm{M}, 0.25 \mathrm{mmol})$ in benzene at $0^{\circ} \mathrm{C}$. After $0.5 \mathrm{~h}$, MMA $(1.2 \mathrm{~g}, 12 \mathrm{mmol})$ was introduced and the reaction was continued for $2 \mathrm{~h}$ at $0^{\circ} \mathrm{C}$. After adding a small amount of methanol, the reaction mixture was poured into a large excess of methanol, and no methanol insoluble polymer was found.
MPV Reduction of Benzaldehyde with a Solution of $\mathrm{Ce}(\mathrm{O} i-\mathrm{Pr})_{3}$ (2) System in Pentane (eq 1$)$

To a solution of the cluster of $\mathbf{2}$ in pentane $(0.05 \mathrm{M}, 0.1 \mathrm{mmol})$ was added benzaldehyde $(52 \mathrm{mg}, 0.49 \mathrm{mmol})$ at room temperature. After being stirred for $1 \mathrm{~h}, 1 \mathrm{~N} \mathrm{HCl}(5 \mathrm{~mL})$ was added, and the organic layer was extracted with ether, dried over anhydrous $\mathrm{MgSO}_{4}$, and concentrated. The crude product was purified by column chromatography on silica gel (hexane-ethyl acetate $10: 1$ to $5: 1$ ) to afford benzyl alcohol (31 mg, 58\% yield).

\section{Polymerization of MMA with 2 System to Obtain the Oligo-MMA}

To a solution of MMA $(1.4 \mathrm{~g}, 14 \mathrm{mmol})$ in toluene $(10 \mathrm{~mL})$ was added a solution of 2 system $(0.05 \mathrm{M}, 0.15 \mathrm{mmol})$ at $0^{\circ} \mathrm{C}$. After $10 \mathrm{~min}$, the reaction was terminated by adding a small amount of methanol, and then the mixture was poured into a large excess of methanol containing a small amount of $1 \mathrm{~N}$ $\mathrm{HCl}$. The methanol soluble part was separated by centrifuge, and concentrated. To the obtained residue was added hexane, and insoluble part was collected. The methanol soluble and hexane insoluble part was dissolved in $\mathrm{CHCl}_{3}$ and filtered. After concentration and vacuumdrying, the oligomer was obtained $(0.11 \mathrm{~g}, 8 \%$ yield). The methanol insoluble polymer was obtained in $85 \%$ yield after freeze-drying $\left(\mathrm{mm} / \mathrm{mr} / \mathrm{rr}=77 / 17 / 6, M_{n}=4.2 \times 10^{4}, M_{w} / M_{n}=\right.$ 3.2).

\section{RESULTS AND DISCUSSION}

\section{Structure of Initiator}

First, the cerium triisopropoxide (2) prepared by the Kagan's method ${ }^{1}$ was carefully analyzed. The concentrations of each ion determined by inductively coupled plasma (ICP) measurement and titration with silver nitrate were as follows:

$\mathrm{Ce}^{3+}=0.05 \mathrm{M}, \mathrm{Li}^{+}=0.68 \mathrm{M}, \mathrm{Cl}^{-}=0.12 \mathrm{M}$ 
The alkoxides, $\mathbf{1}$ and $\mathbf{2}$ in pentane solution used in this study showed characteristic dark red color and the UV-spectra of $\mathbf{2}$ in pentane are shown in Figure 1. The intense absorption spreads in the area of visible radiation. The molecular weight of $\mathbf{2}$ determined by cryoscopic method in benzene was $1010-1240$. These observations indicate that a plausible species may be a cluster having a molecular weight $1195-1237$ as follows ${ }^{8}$ :
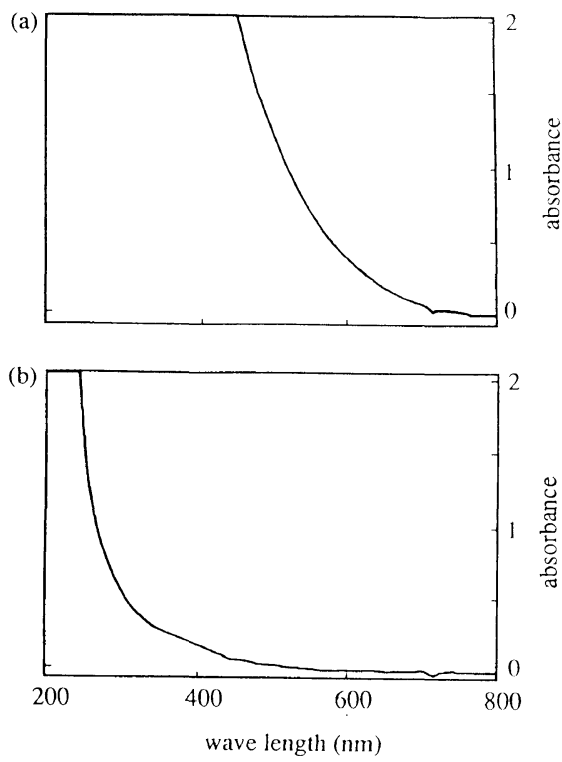

Figure 1. UV spectra of a solution of $\mathrm{Ce}(\mathrm{O} i \text {-Pr })_{3}$ (2) system in pentane/hexane prepared by the Kagan's method (a); diluted to $1 / 10$ by adding pentane (b).

Table I. Polymerization of MMA with metal isopropoxides in toluene ${ }^{a}$

Entry $\quad \mathrm{M}(\mathrm{O} i-\mathrm{Pr})_{n} \frac{\text { Yield }^{\mathrm{b}}}{\%} \frac{\text { Tacticity }}{m m: m r: r r} \frac{M_{n}}{\times 10^{4}} M_{w} / M_{n}$

\begin{tabular}{llrccc}
\hline 1 & $\mathrm{LiO} i$-Pr & 0 & - & - & - \\
2 & $\mathrm{Al}(\mathrm{O} i \text {-Pr })_{3}{ }^{\mathrm{c}, \mathrm{d}}$ & 0 & - & - & - \\
3 & $\mathrm{La}(\mathrm{O} i-\mathrm{Pr})_{3}(\mathbf{1})^{\mathrm{e}}$ & 93 & $80: 15: 5$ & 4.0 & 1.9 \\
4 & $\mathrm{Ce}(\mathrm{O} i-\operatorname{Pr})_{3}(2)^{\mathrm{e}}$ & 89 & $79: 16: 5$ & 4.1 & 2.6
\end{tabular}

a Conditions: $0^{\circ} \mathrm{C}, 1 \mathrm{~h} .{ }^{\mathrm{b}}$ Methanol insoluble part. ${ }^{\mathrm{c}}[\mathrm{MMA}] /\left[\mathrm{M}(\mathrm{O} i \text {-Pr })_{n}\right]=40$. ${ }^{\mathrm{d}}$ Diethylzinc (1 equiv) was used as a co-initiator. ${ }^{\text {e }}$ Prepared by the Kagan's method. $[\mathrm{MMA}] /\left[\mathrm{M}(\mathrm{O} i-\mathrm{Pr})_{n}\right]=c a .140$.

$$
\left[\mathrm{Ce}(\mathrm{O} i-\mathrm{Pr})_{3} \cdot(\mathrm{LiO} i-\mathrm{Pr})_{12} \cdot(\mathrm{LiCl})_{2-3}\right]
$$

\section{Polymerization}

The results of the polymerization of MMA with various metal isopropoxides in toluene are summarized in Table I. Although lithium and aluminum reagents, which are commonly used in MPV reduction, afforded no polymer at $0^{\circ} \mathrm{C}$ (entry 1 and 2), the lanthanoid triisopropoxides (1 and 2) systems, prepared by the Kagan's method, ${ }^{1}$ gave rise to poly(MMA) in good yields (entry 3 and 4 ). The obtained polymers were rich in meso $(\mathrm{mm})$-triad (about $80 \%$ ), and possessed wide polydispersities $\left(M_{w} / M_{n}=\right.$ 1.9-2.6) presumably due to slow initiation (Figure 2). ${ }^{9}$

The cerium triisopropoxide (2) system was also applied for the polymerization of benzyl methacrylate (BnMA) in toluene. The results are shown in Table II. Some characteristic

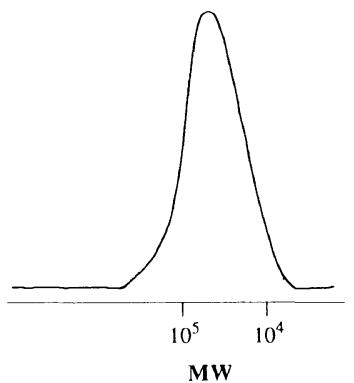

Figure 2. GPC curve of PMMA obtained by $\mathrm{La}(\mathrm{O} i-\mathrm{Pr})_{3}$ (1) system in toluene (Table I, entry 3 ).

Table II. Polymerization of benzyl mechacrylate in toluene using $\mathrm{Ce}(\mathrm{O} i \text {-Pr })_{3}(2)$ system prepared by the Kagan's method ${ }^{a}$

\begin{tabular}{|c|c|c|c|c|c|c|}
\hline \multirow{2}{*}{ Entry } & Temp & Time & Yield $^{\mathbf{b}}$ & Tacticity & $M_{n}$ & \multirow{2}{*}{$M_{w} / M_{n}$} \\
\hline & ${ }^{\circ} \mathrm{C}$ & $\min$ & $\%$ & $m m: m r: r r$ & $\times 10^{4}$ & \\
\hline 1 & 0 & 5 & 66 & $72: 22: 6$ & 4.2 & 7.5 \\
\hline 2 & 0 & 10 & 89 & $74: 21: 5$ & 4.5 & 10.3 \\
\hline 3 & 0 & 180 & 100 & $74: 21: 5$ & 5.1 & 9.6 \\
\hline 4 & -40 & 180 & 100 & $76: 19: 5$ & 42.1 & 3.6 \\
\hline 5 & -78 & 300 & 26 & $42: 37: 21$ & 10.8 & 6.0 \\
\hline
\end{tabular}

${ }^{\mathrm{a}}[\mathrm{BnMA}] /[2]=140 .{ }^{\mathrm{b}}$ Methanol insoluble part. 
Table III. Polymerization of MMA with metal isopropoxides in tetrahydrofuran (THF)

\begin{tabular}{|c|c|c|c|c|c|c|c|}
\hline \multirow{2}{*}{ Entry } & \multirow{2}{*}{$\mathrm{M}(\mathrm{O} i-\mathrm{Pr})_{n}$} & Temp & Time & Yield $^{\mathrm{a}}$ & Tacticity & $M_{n}$ & \multirow{2}{*}{$M_{w} / M_{n}$} \\
\hline & & ${ }^{\circ} \mathrm{C}$ & $\mathrm{h}$ & $\%$ & $m m: m r: r r$ & $\times 10^{4}$ & \\
\hline 1 & $\mathrm{LiO} i-\mathrm{Pr}^{\mathbf{b}}$ & 0 & 2 & 0 & - & - & - \\
\hline 2 & $\mathrm{Ce}(\mathrm{O} i-\mathrm{Pr})_{3}(2)^{\mathrm{c}}$ & 0 & 2 & 72 & $13: 37: 50$ & 2.7 & 1.5 \\
\hline 3 & $\mathbf{2}^{\mathrm{c}}$ & -40 & 3 & 91 & $13: 34: 53$ & 6.2 & 1.3 \\
\hline
\end{tabular}

${ }^{a}$ Methanol insoluble part. ${ }^{b}$ Polymerization was carried out using an initiator ( 1 equiv) and MMA (30 equiv).

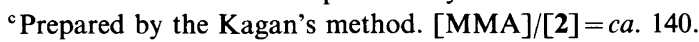

features of the polymerization are as follows. (1) Poly(BnMA)s were obtained in good yields at $0^{\circ} \mathrm{C}$ and $-40^{\circ} \mathrm{C}$ (entry $1-4$ ), but the yield was low at $-78^{\circ} \mathrm{C}$ (entry 5). (2) The isotactic $(\mathrm{mm}=72-76 \%)$ polymers were obtained at $0^{\circ} \mathrm{C}$ and $-40^{\circ} \mathrm{C}$, while the polymer obtained at $-78^{\circ} \mathrm{C}$ showed lower stereoregularity (nearly atactic). (3) All polymers had wide polydispersity, which has also been observed in the polymerization with alkoxide anions. ${ }^{9}$

The polymerization of MMA was also performed in THF with the metal isopropoxides (Table III). Lithium isopropoxide also gave no polymer in $\mathrm{THF}$ at $0^{\circ} \mathrm{C}$ (entry 1). However, syndiotactic poly(MMA) $(r r=53 \%)$ was obtained even at $-40^{\circ} \mathrm{C}$ using the cerium triisopropoxide (2) system in $91 \%$ yield (entry 3).

The results of the polymerization with 1 and $\mathbf{2}$ systems in Tables I-III are similar to those of the polymerization by lithium reagents, ${ }^{9,10}$ although lithium isopropoxide alone did not initiate the polymerization of methacrylic esters. The lithium free lanthanum triisopropoxide (3) system prepared from lanthanum chloride and sodium isopropoxide according to the literature ${ }^{7}$ possessed no ability to initiate the polymerization of MMA in toluene at $0^{\circ} \mathrm{C}$ even in the presence of an excess of lithium isopropoxide. Further, the effect of $\mathrm{LiCl}$ in the polymerization of MMA was also investigated using $3-\mathrm{LiCl}(1: 1)$ and $\mathrm{LiO} i-\mathrm{Pr}-\mathrm{LiCl}(1: 1)$ as initiators, and these also afforded no polymer at $0^{\circ} \mathrm{C}$ for $2 \mathrm{~h}$ in toluene, respectively. These results support the possibility that the active species may be a cluster, which should play an important role in the polymerization, especially in the initiation step.

\section{Study on Initiation Step}

Kagan and co-workers reported that the lanthanoid triisopropoxides effectively catalyze MPV reduction: for example, the reaction of 2-octanone with one-pot prepared cerium triisopropoxide $(10 \mathrm{~mol} \%)$ was performed in 2-propanol to yield 2-octanol in $95 \% .^{1}$ This was confirmed in the reaction of benzaldehyde with 2 system $(20 \mathrm{~mol} \%)$ in pentane at room temperature as described in Experimental Section (eq 1), suggesting that the lanthanoid triisopropoxides (1 and 2) systems have an ability as reducing reagents by hydride transfer even in a mild condition and the polymerization of methacrylic esters with them may be initiated through MPV reduction mechanism; eq 2 .

$$
\begin{gathered}
\mathrm{PhCHO}+\mathrm{M}(\mathrm{O} i \text {-Pr })_{n} \underset{\text { pentane }}{\stackrel{\mathrm{H}^{+}}{\longrightarrow}} \stackrel{\stackrel{\text {.t. }}{\longrightarrow}}{\mathrm{PhCH}_{2} \mathrm{OH}+\left(\mathrm{CH}_{3}\right)_{2} \mathrm{C}=\mathrm{O}}
\end{gathered}
$$

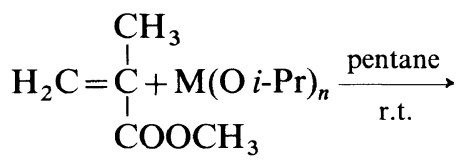

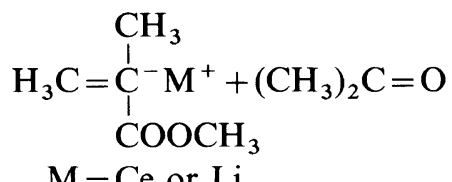


To confirm the above reaction, we attempted to detect acetone, which is generated by MPV reduction as a volatile by-product, in the polymerization of MMA with 2 system. The polymerization of MMA was first conducted at $0^{\circ} \mathrm{C}$ for $2 \mathrm{~h}^{11}$ and then the reaction mixture was distilled under high-vacuum with a liquid $\mathrm{N}_{2}$ trap. The concentration of acetone in the reaction system is roughly estimated about up to $0.01 \mathrm{wt} \%$ theoretically. The distillate was analyzed by GC (Figure 3) and GC-MS (Figure 4). In the GC chart, a small peak of acetone was found at $7.7 \mathrm{~min}$, and the mass spectrum showed a peak of 58 which can be assigned to the $\left(\mathrm{M}^{+}\right)$ion of acetone. These results indicate that MPV reduction took place in the polymerization. In addition, the oligomers (methanol soluble and hexane insoluble part) prepared from MMA and 2 system were analyzed by field desorption mass spectrometry (FDMS) and the peaks of mass numbers of 602 ,

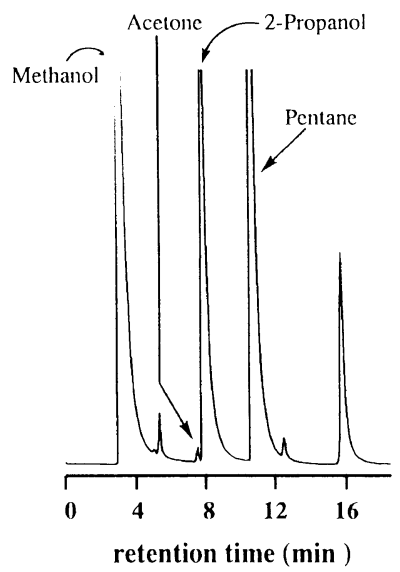

Figure 3. Gas chromatogram of the vacuum-distilled reaction mixture of $\mathrm{MMA}$ and $\mathrm{Ce}(\mathrm{O} i-\mathrm{Pr})_{3}$ (2) system (carrier gas, $\mathrm{He}\left(1.0 \mathrm{~kg} \mathrm{~cm}^{-2}\right)$; column temp : initial temp = $140^{\circ} \mathrm{C}$; final temp $=170^{\circ} \mathrm{C}$; rate $=1^{\circ} \mathrm{C} / \mathrm{min}$ )

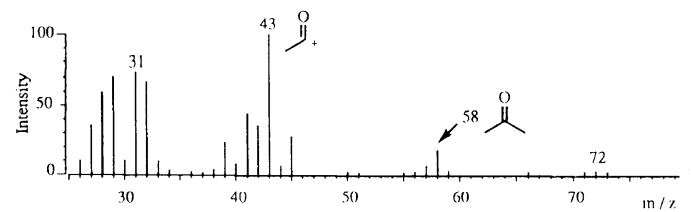

Figure 4. GC-MS spectrum of the vacuum-distilled reaction mixture of MMA and $\mathrm{Ce}(\mathrm{O} i \text {-Pr })_{3}$ (2) system.
$702,802,903$, and 1003 corresponding to the following fragments were confirmed in the spectrum:

$$
\begin{aligned}
& {[{ }^{\mathrm{H}} \overbrace{\mathrm{CO}_{2} \mathrm{Me}}^{\mathrm{H}_{n}^{\mathrm{H}}}]^{+}} \\
&
\end{aligned}
$$

Figure 5(a) shows the ${ }^{1} \mathrm{H}$ NMR spectrum of the above oligomer mixture. Although it is insufficient to assign the end group, the peaks due to isopropyl ether $\left(\mathrm{Me}_{2} \mathrm{C} \underline{\mathrm{H}}-\mathrm{O}-\mathrm{CH}_{2}-\mathrm{C}\right)$ are not detected. Further, the signals are well coincident with the spectrum of PMMA obtained by using lithium enolate of methyl isobutylate as an initiator (Figure 5(b)). ${ }^{12}$ Therefore, it is concluded that the polymerization is initiated by hydride anion $\left(\mathrm{H}^{-}\right)$resulting from the MPV reduction by the lanthanoid (III) triisopropoxides (1 and 2) systems. The tacticities of the polymers obtained in toluene and THF are similar to those of the corresponding polymers prepared with butyllithium. ${ }^{10}$ This suggests that during the propagation the counter ion of an active species may
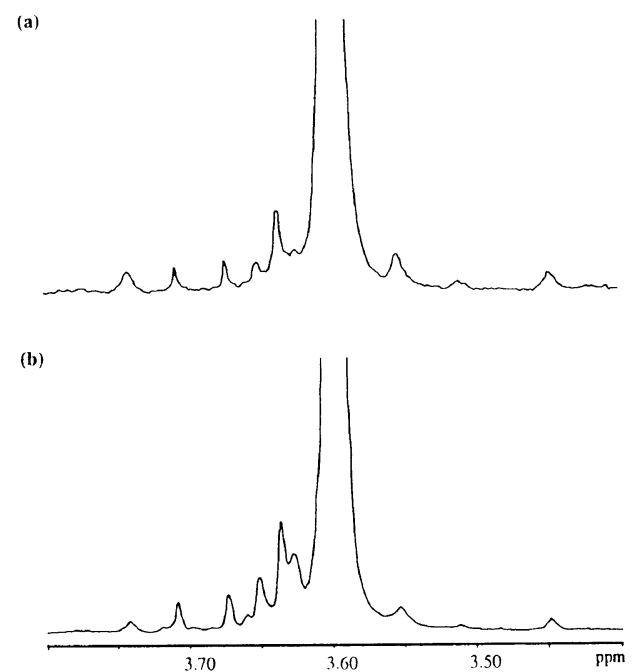

Figure 5. ${ }^{1} \mathrm{H}$ NMR spectra of oligo-MMA (methanol soluble and hexane insoluble part) polymerized with $\mathrm{Ce}(\mathrm{O} i \text {-Pr })_{3}$ (2) system (a) and PMMA initiated by lithium enolate of methyl isobutylate (b). 
be a lithium ion.

In conclusion, the lanthanoid triisopropoxides prepared by the Kagan's method should be a cluster including lithium isopropoxide and lithium chloride as described above. The polymerization of methacrylic esters with them is promoted smoothly to provide isotactic polymers in toluene and syndiotactic ones in THF, and it's initiation reaction takes place in MPV reduction system. The counter ion in the propagation step may be lithium ion. Further work on the structure and reaction mechanism of the lanthaniod triisopropoxides is under current investigation.

Acknowledgments. We are indebted to Professor H. Haraguchi and Mr. H. Sawatari of Nagoya University for the ICP measurement. This work was partly supported by the Grant-in-Aid for Scientific Research on Priority Area of Reactive Organometallics No. 05236103 from the Ministry of Education, Science, and Culture of Japan.

\section{REFERENCES AND NOTES}

1. A. Lebrun, J.-L. Namy, and H. B. Kagan, Tetrahedron Lett., 32, 2355 (1991).

2. a) C. F. Graauw, J. A. Peters, H. Bekkum, and J. Huskens, Synthesis, 1007 (1994); b) R. M. Kellogg, "Comprehensive Organic Synthesis," Vol. 8, B. M. Trost and I. Fleming, Ed., Pergamon Press, Oxford, 1991, p 88 and references therein.

3. a) A. Streitwieser, Jr., J. R. Wolfe, Jr., and W. D. Schaeffer, Tetrahedron, 6, 338 (1959); b) D. Nasipuri and G. Sarker, J. Indian Chem. Soc., 44, 165 (1967); c) P. Kvintovics, B. R. James, and B. Heil, J. Chem. Soc., Chem. Commun., 1810 (1986); d) S. Gladiali, G. Chelucci, G. Chessa, and G. Deloga, J. Organomet. Chem., 327, C15 (1987); e) G. Zassinovich and G. Mestroni, J. Mol. Catal., 42, 81 (1987).
4. a) H. B. Kagan and J. Namy, Tetrahedron, 42, 6573 (1986); b) T. Imamoto, "Comprehensive Organic Synthesis," Vol. 1, B. M. Trost, I. Fleming, and S. L. Schreiber, Ed., Pergamon Press, Oxford, 1991, p 231 ; c) G. A. Molander, "Comprehensive Organic Synthesis," Vol. 1, B. M. Trost, I. Fleming, and S. L. Schreiber Ed, Pergamon Press, Oxford, 1991, p 251; d) G. A. Molander, Chem. Rev., 92, 29 (1992); e) J. R. Long, Aldrichimica Acta, 18, 87 (1985).

5. A. Merbach, M.-N. Pitteloud, and P. Jaccard, Helv. Cim. Acta, 55, 44 (1972).

6. F. A. Bovey, In "Chain Structure and Conformation of Macromolecules," Academic Press, New York, N.Y., 1982, pp 47-60.

7. a) R. C. Mehrotra and J. M. Batwara, Inorg. Chem., 9, 2505 (1970); b) U. D. Tripathi, J. M. Batwara, and R. C. Mehrotra, J. Chem. Soc. (A), 991 (1967); See also c) K. S. Mazdiyasni, C. T. Lynch, and J. S. Smith, Inorg. Chem., 5, 342 (1966); d) L. M. Brown and K. S. Mazdiyasni, Inorg. Chem., 9, 2783 (1970); For reviews, see e) R. C. Mehrotra, A. Singh, and U. M. Tripathi, Chem. Rev., 91, 1287 (1991).

8. The clusters seem unstable, since the dark red colors of the alkoxides (1 and 2 ) gradually disappeared accompanying with a decrease of the polymerization activity during the storage under an atmosphere of argon at room temperature.

9. a) J. Trekoval, Collect. Czech. Chem. Commun., 42, 1529 (1977); b) L. Lochamann, D. Doskocilova, and J. Trekoval, ibid., 42, 1355 (1977); c) J. Trekoval, J. Polym. Sci., Part A-1, 9, 2375 (1971).

10. H. Yuki and K. Hatada, Adv. Polym. Sci., 31, 1 (1979).

11. The polymerization was carried out using MMA $(12 \mathrm{mmol})$ with $2(0.085 \mathrm{mmol})$ in toluene $(10 \mathrm{~mL})$ at $0^{\circ} \mathrm{C}$ for $2 \mathrm{~h}$, and then the reaction was terminated by adding a small amount of methanol $(0.1 \mathrm{~mL})$.

12. The polymerization was carried out using MMA $(14 \mathrm{mmol})$ and lithium enolate of methyl isobutylate $(0.28 \mathrm{mmol})$, prepared from lithium diisopropylamide and methyl isobutylate in ether, in toluene at $0^{\circ} \mathrm{C}$ ( $80 \%$ yield on methanol insoluble polymer, $\mathrm{mm} / \mathrm{mr} /$ $r r=67 / 24 / 9)$. See a) L. Lochmann, J. Trekoval, and A. H. E. Müller, Makromol. Chem., 185, 1819 (1984); b) C. B. Tsvetanov, A. H. E. Müller, and G. V. Schulz, Macromolecules, 18, 863 (1985); c) A. H. E. Mller, L. Lochmann, and J. Trekoval, Makromol. Chem., 187, 1473 (1986). 